\title{
Estímulos à pesquisa histórica sobre o caratê-dô: Shotokan's Secret, de Bruce D. Clayton
}

\author{
Carlos Herold Junior ${ }^{*}$
}

\begin{abstract}
Resumo: Esta resenha analisa a obra Shotokan's Secret, de Bruce D. Clayton. A partir de um diálogo com outros estudos, verificamos que ela oferece um importante estímulo para pesquisas históricas sobre o caratê-dô.

Palavras-chave: Caratê. História das artes marciais. Budo.
\end{abstract}

Embora se reconheça que o interesse pelas artes marciais no Brasil já se tornou um "grande empreendimento social"(CORREIA; FRANCHINI, 2010, p. 3), o estímulo para estudos de maior amplitude faz com que análises publicadas em outros países sejam bem-vindas, pois "[...] podemos sublinhar a necessidade premente de ampliação e diversificação na produção de conhecimento acadêmico relativo ao universo das L/AM/MEC"1.(CORREIA; FRANCHINI, 2010, p. 6). Os quatro anos transcorridos entre o levantamento de Correia e Franchini (2010) e a atualidade não impedem que as constatações ganhem ainda mais força, quando o que se quer abordar é a história das artes marciais. Nesse sentido, a reedição ${ }^{2}$ da obra de Bruce D. Clayton, Shotokan's Secret: the hidden truth behind Karate's fighting origins ${ }^{3}$ (CLAYTON, 2010) é um fato valioso para quem se interessa pelas modalidades gestadas sob a influência da realidade japonesa no fim do século XIX e início do XX. Esse valor poderá ser percebido no diálogo metodológico que a obra em questão poderá fomentar com estudos

\footnotetext{
‘Universidade Estadual de Maringá, Maringá, PR. E-mail: carlosherold@hotmail.com

${ }^{1}$ Lutas, artes marciais e modalidades de esporte de combate.

${ }^{2}$ Trata-se de uma versão revista e ampliada. A primeira edição foi publicada em 2004.

${ }^{3}$ Tradução livre: $\mathrm{O}$ segredo do Shotokan: a verdade escondida nas origens da luta de caratê.
} 
produzidos no Brasil que, igualmente, possuem foco na história do caratê-dô, tal como os artigos de Barreira e Massimi (2003), Souza (2013) e, principalmente, Frosi e Mazo (2011).

Shotokan's Secret, a partir de próprio título, já sinaliza uma postura bastante conhecida no campo das artes marciais: a intenção de revelar um segredo colocando a obra como definitiva, ou não sujeita aos erros incorridos por todas as outras. Soma-se a esse traço a recorrente disputa pelas "origens", pelo o que os historiadores nutrem uma justa suspeita, mas que fascina não apenas Clayton, mas praticantes e analistas ${ }^{4}$.

A trajetória de Clayton também é característica de muitos que publicam livros e artigos sobre as artes marciais: o autor americano possui uma vasta lista de elevadas graduações em muitas modalidades de luta. Ele também é doutor em ecologia, mas o que o levou ao livro em tela tem mais a ver com seu envolvimento prático com as lutas, um traço visto como um diferencial em obras com esse escopo temático. A essa menção elogiosa aos "anos de prática", subjaz a postura que sustenta ser a ação e não as palavras, os livros ou a teoria, a legítima fonte do conhecimento histórico sobre esse assunto. Por que, então, escrever mais um livro sobre essa prática ${ }^{5}$ ? Talvez para lidar com esse dilema de criticar as palavras redigindo outras tantas, Shotokan's Secret lança mão, em uma postura também muito comum, em quase metade das páginas livro, de fotos: elas retratam golpes de caratê-dô, mostrando o autor (e seus discípulos) em ação no seu dia a dia de aulas e treinamentos.

\footnotetext{
${ }^{4}$ Frosi e Mazo (2011, p. 304), mesmo assumindo uma perspectiva analítica baseada na história cultural, iniciam a abordagem de "alguns equívocos" sobre a história do caratê-dô afirmando: "Primeiramente é necessário expor um ponto na maioria dos textos sobre o Karate: a definição de suas origens".

${ }^{5} \mathrm{Ao}$ observar esse traço, não ambicionamos avaliar a importância ou limite da obra pela trajetória formativa do autor. Apenas queremos apresentar uma característica marcante do que se escreve e de quem escreve sobre as artes marciais, mantendo à frente as análises de Anglo (2000). Ao estudar as artes marciais na Europa durante o renascimento, Anglo (2000) lembra que o legendário samurai Miyamoto Musashi (1584-1645) afirmava a necessidade que deveria ter todo verdadeiro guerreiro de dominar a pena tão bem quanto a espada (postura também observada em muitos especialistas em artes marciais na Europa, que redigiam livros sobre aquilo que praticavam). Essa lembrança da parte de Anglo (2000) evidencia que essa relação de complementariedade entre o mundo das batalhas e o das letras também é vista na Europa dos séculos XVI e XVII.
}

Movimento, Porto Alegre, v. 20, n. 4, p. 1655-1663, out./dez. de 2014. 
Estímulos à pesquisa histórica sobre o caratê-dô...

Todavia, Shotokan's Secret também se distancia do que estamos acostumados a encontrar nos livros escritos por professores de artes marciais. O livro tem 12 capítulos, com quase 400 páginas. Além de uma bibliografia volumosa e relevante sobre a história de Okinawa, do Japão e do caratê-dô, há um índice onomástico que permite acesso rápido às informações. Como se essas positividades já não fossem o bastante, temos o fato de o autor conhecer a ilha de Okinawa por ter ido até lá várias vezes, além de possuir conhecimento linguístico para analisar os desdobramentos históricos do desenvolvimento do caratê em Okinawa, sua chegada ao Japão e sua expansão pelo Mundo.

Para Clayton o desenvolvimento do caratê no século XIX em Okinawa explica-se pela situação política do arquipélago, posicionado subalternamente tanto à China quanto ao Japão e, sobretudo, constantemente vítima dos choques entre as duas potências. Essa posição política e a necessidade de sobreviver apesar dela teriam tornado o palácio do governo de Okinawa um locus privilegiado para o desenvolvimento de técnicas de combate sem a posse de armas. Afinal, elas eram proibidas aos habitantes da ilha, assim como à guarda responsável pela defesa do rei e ao próprio governo daquela realidade. A questão prática que se colocava, então, era a condição de enfrentar pessoas e exércitos armados, usando apenas o próprio corpo e/ ou pequenos armamentos ${ }^{6}$. Se a posse da espada era proibida aos okinawanos, era contra elas que deveriam lutar, em caso de necessidade. Desse ponto de vista, argumenta Clayton (2010, p. 203), pontapés e socos eram de pouca utilidade, a não ser nos momentos de finalização dos combates, depois que os inimigos já estavam desarmados ou sem condições de usar o "aço contra a pele" daqueles que se defendiam sem nenhum armamento. E é nesse momento que o autor busca apresentar e justificar a sua análise sobre a importância dos cinco primeiros kata, bem como a interpretação a ser dada a cada um de seus movimentos. Do ponto ${ }^{6}$ Clayton (2010, p. 343) esforça-se por afirmar que a sua investigação histórica sustenta a ideia
de que "Karate isn't Empty-Handed".

Movimento, Porto Alegre, v. 20, n. 4, p. 1655-1663, out./dez. de 2014. 
de vista técnico, a consequência mais visível é que a combinação da maioria dos golpes de contato que se vê nesses kata transformase em situações de mobilizações, desarmamentos e luxações, com o fito de deixar o inimigo ou morto ou sem qualquer condição de continuar o combate. São elas as únicas possibilidades concretas de alguém desarmado fazer frente a um habilidoso espadachim, de acordo com o guerreiro-autor especialista em sobrevivência: "The 'empty hand' is for sporting events. Real karate, as seen in the heian applications, is intimately involved with military weapons" $"$ (CLAYTON, 2010, p. 343).

O conjunto dessas informações, avaliado como formador da base do caratê-dô Shotokan, choca-se contra o que Clayton (2010, p. 62) chama de lendas ou mitos aceitos entre praticantes e estudiosos do caratê-dô: a de que as origens do caratê remontariam à uma antiga herança chinesa. Por isso, defende-se a ideia de que o caratê-dô formou-se no século XIX no interior da nobreza de Okinawa (e não de seus camponeses, conforme afirma, também, a "lenda") e na sua luta por manter alguma soberania perante inimigos tão poderosos do ponto de vista econômico e militar, principalmente, na luta contra os "samurai oppressors" ou os “japanese tormentors”(CLAYTON, 2010, p. 69).

Se a presença do domínio japonês na ilha acabou sendo um dos grandes estimuladores para o desenvolvimento das técnicas que sustentaram o posterior desenvolvimento do caratê, essa formação foi posta em prática no estado de prontidão gerado durante a presença do Comodoro Perry (1784-1858) na ilha, em 1853. Clayton utiliza desenhos e relatos feitos pelos americanos e, também, alguns feitos pelos habitantes de Okinawa à época. Grande atenção é dada ao diário de viagem redigido por Perry ${ }^{8}$ para reconstruir a constrangedora presença do americano, nisso que se

\footnotetext{
7Tradução livre: A "mão vazia" é para os eventos esportivos. O verdadeiro caratê, como visto nas aplicações dos heians, está intimamente envolvida com armas militares.

${ }^{8}$ Publicado com o título Narrative of the expedition of an American squadron to the China Seas and Japan, performed in the years 1852, 1853 and1854, under the command of Commodore $M$. C. Perry, United States Navy, o diário está disponível na internet: http://ebook.lib.hku.hk/CTWE/ B36599566/ Acesso em 13 set. 2013.
}

Movimento, Porto Alegre, v. 20, n. 4, p. 1655-1663, out./dez. de 2014. 
tornou o momento emblemático da abertura do oriente às forças bélicas do ocidente, mormente, as americanas.

A ocasião é estudada e narrada com grande habilidade, fazendo com que essa parte do livro seja a mais cativante. Nela lemos que a guarda real de Okinawa trabalhou servindo comida e bebida (de qualidade propositalmente duvidosa) aos invasores nos "eventos diplomáticos" que se seguiram à chegada da poderosa esquadra. A partir de fontes pictográficas, o autor demonstra que o que se assume como meros cortesãos eram guerreiros treinados na arte da "mão chinesa", prontos para atacar os convivas e seu líder, ou defender seu chefe supremo. O comando dessa guarda era de responsabilidade de quem Clayton chama da "Lords of Karate": Itosu (1831-1915), Asato (1827-1906), Chotoku Kyan (18701945), Kanryo Higaonna (1853-1916), Chojun Miyagi (18881953), e, sobretudo, Matsumura (1797-1899), que é assumido como o maior responsável pela criação e aperfeiçoamento da maioria dos kata hoje praticados no caratê. Interessante verificar que a análise linguística demonstra que shoto, o apelido de Funakoshi e que formou o nome do estilo por ele criado (Shotokan), é uma variação linguística de Matsu, que é a base de Matsumura que, por sua vez, é um nome que significa "pinheiro", o que explicaria a importância dessa árvore como uma imagem bastante conhecida dos caratecas. Com isso Clayton secundariza Funakoshi na criação do caratê e dá a Matsumura a condição de mentor das bases técnicas do caratêdô Shotokan, fortemente calcadas nos cinco primeiros kata, que foram, posteriormente, apenas "divulgados" por Funakoshi ao Japão e a todo o mundo. Eis, então, o Shotokan's Secret!

A tese e a sua comprovação estão muita sujeitas a contestação. Mesmo com a utilização da pictografia, da planta do castelo real de Okinawa (CLAYTON, 2010, p. 171), da linguística e dos diários de Perry, ainda lidamos com um terreno muito sujeito a especulações. É importante sublinhar que o próprio autor afirma a necessidade

${ }^{9}$ Palavra chinesa que significa "mão chinesa", mesmo quando lida na transliteração japonesa e koreana. Funakoshi (1868-1957), intencionando melhorar a divulgação das técnicas ao público japonês, mantém a pronúncia da palavra em japonês (Kara te), alterando o desenho dos diagramas, originando o significado atual: "mãos vazias".

Movimento, Porto Alegre, v. 20, n. 4, p. 1655-1663, out./dez. de 2014. 
de ser especulativo. Afinal, Okinawa foi arrasada (CLAYTON, 2010, p. 154) durante a Segunda Guerra e, consequentemente, quase a totalidade de indícios que poderiam endossar ou refutar de forma mais contundente hipóteses como as que lemos em Shotokan's Secret foi destruída. Se a escassez de documentação é algo que incomoda os historiadores de uma maneira geral, quando a questão são as práticas corporais e, especificamente, o caratêdô, a problemática torna-se ainda mais aguda. Tan (2004) vai ao encontro dessa advertência feita por Clayton, ao dizer que:

$[\ldots]$ any attempt to trace or reconstruct karate's historical trajectory is often harder than it appears. This becomes increasingly apparent from the lack of any detailed or specifically written records pertaining to its technical evolution. Such a state of affairs is also due to the fact that the learning of martial arts, prior to the 20th century in general, has been largely transmitted orally and through corporeal practice, as opposed to being part of a textual tradition of recording ${ }^{10}$ (TAN, 2004, p. 172).

Nesse ponto, Frosi e Mazo (2010, p. 304) apresentam uma discordância: para os autores brasileiros, a dita escassez de fontes não existe e não pode ser utilizada como explicação das dificuldades ao se abordar a história do caratê-dô. Para eles, uma "simples busca na internet" e um "mínimo de conhecimento de língua inglesa" evitariam o que eles chamam de "tropeços" nos estudos históricos sobre o caratê-dô.

Dissensão importante, mas que sublinha a necessidade de realizar estudos mais sistemáticos sobre a história dessa dimensão da cultura corporal e que valoriza tanto os esforços de Frosi e Mazo (2011), Tan (2004), bem como os potenciais analíticos de Shotokan's Secret: ao estudar a história do caratê-dô Shotokan,

\footnotetext{
${ }^{10}$ Tradução livre: Qualquer tentativa de rastrear ou reconstruir a trajetória histórica de caratê é muitas vezes mais difícil do que parece. Isto torna-se cada vez mais evidente a partir da falta de quaisquer registros detalhados ou especificamente escritos referentes à sua evolução técnica. Tal estado de coisas é também devido ao fato de que a aprendizagem de artes marciais, antes do século 20 , em geral, foi amplamente transmitida oralmente e através da prática corporal, em vez de ser parte de uma tradição textual de registro.
}

Movimento, Porto Alegre, v. 20, n. 4, p. 1655-1663, out./dez. de 2014. 
Clayton reconstrói o contexto okinawano e verifica que, aqueles que nele atuaram, receberam, apropriaram, criaram e modificaram muitas heranças e deixaram muitas outras. Grande lição para compreendermos os processos de formação da cultura corporal que se passa em várias épocas e também tem seu lugar na atualidade, inclusive, de um modo muito visível no campo das artes marciais. Trata-se de um procedimento analítico que também encontra eco nos estudos de Tan (2004), que endossa o valor de se abordar o "complex interplay of Okinawan, Japanese, Chinese, and Western colonizing discourses"11 (TAN, 2004, p. 170). Frosi e Mazo (2011, p. 308) também afirmam que o "Karate não é um fenômeno cultural japonês, mas o resultado de um processo influenciado por várias matrizes culturais". Nesse sentido, Clayton é relativamente bemsucedido ao pôr em relevo a hibridização de práticas e discursos, que hoje se manifesta no grande número de estilos e ramificações dentro dos próprios estilos que vemos no caratê-dô. Nesse ponto, mais uma vez, Clayton corrobora a postura historiográfica de Tan (2004), quando este afirma que os... "constitutive elements of culture or tradition, such as in the case of an alleged 'martial tradition' such as karate, are never necessarily well bounded or rigidly unchanging constructs, especially in the face of political and historical contingencies"12 (TAN, 2004, p.169).

Com isso, temos em mãos boas possibilidades de ampliarmos nosso entendimento sobre os processos históricos que encadeiam arcabouços políticos, culturas e a corporalidade, com grande impacto na compreensão do surgimento e expansão das práticas corporais e nas estratégias formativas nelas baseadas na virada do século XIX ao XX. Essas possibilidades serão enriquecedoras ao assumirmos as dificuldades empíricas e analíticas de se abordar a história do caratê-dô, deixando de vê-las como "combustível

\footnotetext{
${ }^{11}$ Tradução livre: [...] complexa interação de discursos okinawanos, japoneses, chineses e de ocidentais colonizadores.

${ }^{12}$ Tradução livre: "[...]elementos constitutivos da cultura ou da tradição, como no caso de uma suposta 'tradição marcial', como é o caso do karatê, nunca são necessariamente bem delimitados nem construções rigidamente imutáveis, especialmente em face das contingências políticas e históricas."
}

Movimento, Porto Alegre, v. 20, n. 4, p. 1655-1663, out./dez. de 2014. 
para a fornalha de tropeços" (FROSI; MAZO, 2010, p. 297): que sejam limites reconhecidos e encarados com levantamento de fontes primárias e procedimentos metodológicos que considerem e estimulem a intenção de se realizar uma "leitura complexa, abordando as nuances da transmissão e transformação histórica da prática do Karate" (FROSI; MAZO, 2010, p. 297). Na obra de Clayton esses estímulos estão presentes e são muito bem-vindos.

Stimuli for historical research on Karate-do: Bruce D. Clayton's
Shotokan's Secret
Abrstract: This review examines Bruce D. Clayton's work
Shotokan's Secret. Based on a dialogue with other studies, we
found that it offers an important stimulus for historical research on
karate-do.
Keywords: Karate. History of Martial Arts. Budo.

Estímulos para la investigación histórica en el karate-do:
Shotokan's Secret, Bruce D.Clayton
Resumen: Esta revisión examina la obra Shotokan's Secret, de
Bruce D. Clayton. Desde el diálogo con otros estudios, encontramos
que proporciona un importante estímulo para la investigación
histórica sobre el karate-do.
Palabras clave: Karate. Historia de las artes marciales. Budo.

\section{REFERÊNCIAS}

ANGLO, S. The martial arts of renaissance Europe. London: Yale University, 2000.

BARREIRA, C. R. A.; MASSIMI, M. As idéias psicopedagógicas e a espiritualidade no karate-do segundo a obra de Gichin Funakoshi. Psicol. Reflex. Crit., Porto Alegre, v. 16, n. 2, 2003. Disponível em <http://www.scielo.br/scielo.php?script=sci arttext\&pid=S0102-79722003000200018\&lng=en\&nrm=iso>. Acesso em: $15 \mathrm{Abr}$. 2014.

CLAYTON, B. D. Shotokan's secret: the hidden truth behind karate's fighting origins. Cruz Bay: Ohara, 2010.

CORREA, W. R.; FRANCHINI, E. Produção acadêmica em lutas, artes marciais e esportes de combate. Motriz: Revista de Educação Física, Rio Claro, v. 16, p.

Movimento, Porto Alegre, v. 20, n. 4, p. 1655-1663, out./dez. de 2014. 
Estímulos à pesquisa histórica sobre o caratê-dô...

1-9, 2010. Disponível em <http://www.periodicos.rc.biblioteca.unesp.br/index.php/ motriz/article/view/1980-6574.2010v16n1p01/2707>. Acesso em: 10 set. 2013.

FROSI, T. O.; MAZO, J. Z. Repensando a história do karate contada no Brasil. Rev. bras. educ. fís. esporte, São Paulo, v. 25, n. 2, June 2011. Disponível em http:// www.scielo.br/scielo.php?script=sci_arttext\&pid=S1807-55092011000200011\&lng =en\&nrm=iso>. Acesso em: 14 Abr. 2014.

SOUZA, M. F. O caminho-via marcial no cinema japonês: estudos sobre a representação do Budo em Sanshiro Sugata e Kuro Obi. Revista Movimento, Porto Alegre, v. 19, n. 2, p. 327-345, 2013. Disponível em: <http://www.seer.ufrgs. br/index.php/Movimento/article/view/32665>. Acesso em: 14 abr. 2014.

TAN, K. Constructing a Martial Tradition: Rethinking a Popular History of KarateDou, Journal of Sport and Social Issues, Illinois, n. 28; p. 169-192, 2004.

Endereço para correspondência:

Carlos Herold Junior

Rua Marechal Deodoro 530, apto 143. Zona 07.

CEP 87030-020, Maringá-PR.

Recebido em: 16.04.2014

Aprovado em: 14.06.2014

Movimento, Porto Alegre, v. 20, n. 4, p. 1655-1663, out./dez. de 2014. 